\title{
West Virginia Farmers Market Training Network: A case study in connecting markets and resources
}

\author{
Daniel Eades ${ }^{a *}$ and Kelly Nix ${ }^{b}$ \\ West Virginia University Extension Service \\ Kelly Crane ${ }^{\mathrm{c}}$ \\ Friends of Family Farmers
}

Submitted April 22, 2015 / Revised December 11, 2015 / Accepted December 30, 2015 /

Published online May 14, 2016

Citation: Eades, D., Nix, K., \& Crane, K. (2016). West Virginia Farmers Market Training Network:

A case study in connecting markets and resources. Journal of Agriculture, Food Systems, and Community

Development, 6(3), 7-18. http://dx.doi.org/10.5304/jafscd.2016.063.002

Copyright (C) 2016 by New Leaf Associates, Inc.

\begin{abstract}
Farmers markets provide social and economic benefits to farmers and communities. In West Virginia, local food, farm, and community development organizations are collaborating to strengthen local food networks. In this reflective essay we discuss the development and execution of a statewide pilot training program for market managers and volunteer leaders and provide results from first year evaluations. Launched in 2012, the West Virginia Farmers Market Training Network Pilot

\footnotetext{
a * Corresponding author: Daniel Eades, Community Resources and Economic Development; 704 Knapp Hall; West Virginia University; Morgantown, West Virginia 26506-6031 USA; +1304-293-8697; Daniel.Eades@mail.wvu.edu

b Kelly Nix, Community Resources and Economic Development; 702 Knapp Hall; West Virginia University; Morgantown, West Virginia 26506-6031 USA; +1-304-2938680; Kelly.Nix@mail.wvu.edu

c Kelly Crane, Friends of Family Farmers, 249 Liberty Street NE, Suite 212; Salem, Oregon 97301 USA; +1-503-581-7124; kelly@,FriendsofFamilyFarmers.org
}

Program (FMTNPP) was designed to address the needs of 10 markets in various stages of development across the state. Originally envisioned as a direct technical assistance model, the program organizers rapidly recognized the benefits of peerto-peer learning and shifted its focus to a hybrid model that embraced both expert and practitioner knowledge. Today, the program emphasizes shared knowledge creation and problem solving, along with strong networking and data collection components. We believe the lessons and strategies learned during the program's implementation will be valuable for food system organizers and service providers trying to encourage the growth and sustainability of small, rural farmers markets.

\section{Keywords}

farmers markets, market development, producer development, training program, business planning

Disclosure

Kelly Crane is the former director of the West Virginia Farmers Market Association and served in that capacity during the study period described herein. 


\section{Introduction}

In West Virginia, where 75 percent of farms have less than US $\$ 10,000$ in sales annually (United States Department of Agriculture [USDA], National Agricultural Statistics Service, 2014), farmers markets play a critical role in the economic and cultural fabric of the state's local food communities and emerging food economies. Markets serve as essential entry points for beginning producers into the local foods economy, acting as incubators for growing and diversifying food businesses (Cameron, 2007; Feenstra, Lewis, Hinrichs, Gillespie, \& Hilchey, 2003). With low costs of participation (such as an annual fee US $\$ 15$ to US\$30 in many West Virginia counties) and limited barriers to entry, markets allow vendors to test marketing and merchandising skills, evaluate consumer responses to their products, and build a "brand" for their farm valuable in other opportunities, such as agritourism or volume sales.

Local food and farm and community development organizations across West Virginia recognize the impacts farmers markets have on communities and have collaborated to strengthen the network of those involved in improving access to locally produced food. In 2012, the West Virginia Farmers Market Association (WVFMA) launched a statewide initiative, the Farmers Market Training Network Pilot Program (FMTNPP), to address the needs of markets and co-ops in various stages of development. The program linked markets to technical support, established a statewide community of markets, and created a standard tracking system to evaluate program success, while simultaneously increasing the WVFMA's organizational capacity to continue serving markets in the future. Although the program was initially envisioned as a straightforward direct technical assistance program, leadership recognized the value of practitioner expertise and the role market leaders could play in educating both their peers and technical resource providers often unfamiliar with the unique needs of farmers markets and farm based businesses. The program has evolved into a blended approach that emphasizes the roles of both content experts and practitioners, and collaborative knowledge-sharing between markets and technical assistance providers.
This case study outlines the origins of the West Virginia FMTNPP, the programmatic and operational challenges experienced during program development and delivery, the lessons learned and strategies employed to address these challenges, and the ways in which the program has evolved to better meet farmers markets' needs and more effectively deliver training and expertise. There are few examples of face-to-face development programs in the literature and no evaluations of program outcomes. We believe the lessons learned during the WV FMTNPP and the resulting program improvements will be relevant for food system organizers and service providers across the nation, especially those encouraging the growth and sustainability of small and/or rural farmers markets.

\section{The Needs of Market Stakeholders}

Over the past 20 years the number of farmers markets across the country has increased significantly. Data from the United States Department of Agriculture (USDA), Agricultural Marketing Service (AMS) currently list more than 8,000 markets, a 371 percent increase from 1994 (USDA AMS, 2014). While increased demand is good news for markets, many continue to experience obstacles to growth and success. Low et al. (2015) note that between 2007 and 2012 the value of direct-toconsumer sales has remained essentially flat, despite growth in the number of farms reporting direct sales. Research suggests that approximately 50 percent of new markets fail within the first five years (Eggert \& Farr, 2009), and even in more stable markets a lack of training and understanding of topics such as risk management, business planning, producer development, and market structure can dampen success and ultimately lead to market closure (Stephenson, Lev, \& Brewer, 2008; Connell \& Hergesheimer, 2014).

In West Virginia the number of markets roughly tripled over the past decade, from 34 markets in 2005, to 90 markets operating in more than 110 separate locations in 2014 (Gardner, 2014). This rapid growth has increased competition among markets to recruit vendors and growers, especially in the state's rural regions, where numbers are scarce. Additionally, many markets 
experience growing pains with regards to leadership, management, and effective business models. Organized and run by a wide range of entities including volunteer advocates, local governments, community and faith based organizations, or producers themselves, markets have a diversity of experience, funding, facilities, and capacity (Spellman, Lyons, \& Lower, 2012).

Farmers market advocates and stakeholders across the nation recognize that markets' long-term economic viability requires technical experience in business planning and marketing (Tropp \& Barham, 2008). This includes vendors and market leaders' abilities to accurately gauge production costs and prices and to remain current on emerging consumer trends, product varieties, and improved season extension techniques (Tropp \& Barham, 2008). Unfortunately, markets rarely have the internal expertise to provide technical assistance in these key areas or spearhead long-term business planning projects that are necessary for business expansion (Cowee, Curtis, \& Gatzke, 2009).

To overcome these barriers, attendees of the 2007 National Farmers Market Summit in Baltimore, Maryland, recommended that market representatives increase their collaborative efforts with both traditional government and community partners, and reach out to nontraditional community organizations (Tropp \& Barham, 2008). Partnership opportunities identified at the summit include agricultural Extension representatives and state university personnel to address production techniques, emerging technology, and season extension, and local microenterprise development entities for business plan development and training. Successful partnerships, especially with nontraditional organizations, require that markets communicate their public value for individuals and communities. Summit attendees encouraged the development of programs that train market managers and advocates on how to best capture, document, and report information that quantitatively measures a market's impact on the local economy and community.

Eggert and Farr (2009) specifically recommend mentoring and training programs at the regional or market level to strengthen entrepreneurship and marketing skills among vendors. National data from the Farmers Market Coalition indicate that 73 percent of state farmers market associations (FMAs) provide some form of educational resources, including fact sheets, guides, and other materials and technical assistance; however, distribution and use of these resources are often limited to market managers and start-up markets (Wasserman, 2009). Research by the Project for Public Spaces (PPS) (2008) suggests that FMAs are struggling to meet their constituents' evolving needs. The PPS notes that while markets have gained increased support from customers and politicians, and are significant players in sustainable agriculture, "buy-local," and community hunger initiatives, little of this support has translated into increased resources to develop or support the capacity of vendors, market managers, or key partners. The Farmers Market Coalition's 2009 needs assessment identified similar issues, with many FMAs citing insufficient financial and labor resources as significant challenges in identifying, developing, and delivering resources to address market challenges.

\section{The West Virginia Response}

As the sole entity providing support for farmers markets in West Virginia, the WVFMA is recognized as the key organization for addressing farmers market issues and serves as a valuable link between new farmers and the state's and larger agriculture community. When the WVFMA was formed in 2007, its goal was to strengthen the viability of West Virginia farmers markets by fostering cooperation among members and service providers for problem-solving, identifying and adopting best practices, and improving policy and regulations (Spellman et al., 2012). The WVFMA is governed by a volunteer board of directors, composed entirely of managers from member markets, and meets annually with its advisory group, which includes representatives from local foods advocacy groups, community development organizations, and the state's two land-grant institutions.

In 2011 the organization included 30 member markets, less than half of the approximately 80 known farm markets in the state. The organization maintained a website with communication resources and educational materials and hosted 
four, one-day trainings for farmers markets across the state. Its outreach activities included partnering with the WV Department of Health and Human Resources to improve and clarify market foodsafety guidelines; operating a chapter of the Buy Fresh Buy Local program to provide branding and marketing for member markets; and organizing a "Winter Blues Farmers Market" at West Virginia University Extension's annual Small Farm Conference to demonstrate best practices, such as collecting gross sales, accepting EBT and credit cards, and requiring local, producer-only ingredients (Spellman et al., 2012).

In addition to education and outreach, the WVFMA partnered with the USDA to create and update the state's farmers market census. The 2011 census found rapid growth in the number of markets in the state, but also found limited resources and capacity among markets and market managers. Interviews and anecdotal observations suggested that only one-fourth of WV markets were firmly established, "mature" markets with adequate structure and management. An additional one-fourth were classified as "marginal" markets, so small or new that their future success was uncertain. This left approximately half of the state's markets classified as "developing" markets, whose future would be determined largely by their ability to successfully identify and utilize existing energy and resources (Spellman et al., 2012).

Market managers frequently described the isolation they experienced and their struggles to assist producers in planning production and growing sales. Many managers are volunteers and often producers themselves, which limits opportunities for researching or implementing new production and marketing techniques (Spellman et al., 2012). These challenges were well understood by the WVFMA volunteer board, which experienced similar time and resource constraints, especially during the growing season, which limited the organization's ability to sustain and expand yearround assistance and support to member markets (Spellman et al., 2012).

In order to address the needs of producers and markets, and to strengthen the organization's capacity to serve additional markets in the future, the WVFMA partnered with the West Virginia
Food \& Farm Coalition, the West Virginia University Extension Service, and the West Virginia Community Development Hub to develop the Farmers Market Training Network Pilot Program (FMTNPP), a technical assistance program that would integrate components of group training, direct technical assistance, and peer networking. The long-term goal of the project is to strengthen community economies and rural local-food value chains. The program engages three tiers of stakeholders by increasing the profitability of vendors, bolstering the long-term viability of farmers markets, generating data for advocacy, and increasing the membership base and organizational capacity of the WVFMA (Table 1).

\section{Program Development and Delivery}

Program organizers began by surveying state markets and technical assistance providers, and reviewing national market support organizations' previously identified needs and best practices for engagement. Based on published documents and discussions with in-state stakeholders, the WVFMA identified common issues that clustered around four broad areas of need: risk management; business planning and marketing; producer development; and structure and unity (see more detail in the Appendix). A review of market associations' education and outreach activities to address these needs produced a wealth of resources. However, in line with the findings of the Farmers Market Coalition, the depth and breadth of engagement around topics were limited. For example, organizations often provided toolkits or fact sheets, but provided significantly fewer opportunities for in-depth learning and sharing around these topics. In-person trainings were often limited to annual conferences that spanned one or two days and covered an array of topics, or one-off training sessions that only addressed single issues. Frequently, materials or trainings were limited to the needs of a single stakeholder (markets and market managers), ignoring the specific needs of growers and producers. Finally, materials were most often oriented to new markets, rather than the "developing" markets recognized as a target audience by the WVFMA.

While the WVFMA saw room for improvement in the development and delivery of 
Table 1. Stakeholder Engagement in FMTNPP Activities and Expected Outcomes

\begin{tabular}{|c|c|c|}
\hline Stakeholder & Proposed Engagement Activities & Outcomes \\
\hline $\begin{array}{l}\text { Farmers/ } \\
\text { Producers }\end{array}$ & $\begin{array}{l}\text { - Business planning templates } \\
\text { - Consumer data } \\
\text { - Risk management } \\
\text { - New sales opportunities (winter marketing, } \\
\text { partnerships with market buyers) }\end{array}$ & $\begin{array}{l}\text { - Increased sales for vendors } \\
\text { - Market growth }\end{array}$ \\
\hline Farmers Markets & $\begin{array}{l}\text { - Risk management } \\
\text { - Business planning } \\
\text { - Producer development } \\
\text { - Strategic planning and organizational } \\
\text { development } \\
\text { - Standardized data tracking system }\end{array}$ & $\begin{array}{l}\text { - Stronger rural local food value chains } \\
\text { - Incubation and support for vendor } \\
\text { development } \\
\text { - Improved data for advocacy }\end{array}$ \\
\hline $\begin{array}{l}\text { West Virginia Farmers } \\
\text { Market Association }\end{array}$ & $\begin{array}{l}\text { - Increased collaborations with partner } \\
\text { organizations } \\
\text { - Resources to hire full-time staff } \\
\text { - Board development } \\
\text { - Training for strategic and financial sustainability }\end{array}$ & $\begin{array}{l}\text { - Increased organizational capacity } \\
\text { - WV Farmers Market Toolkits } \\
\text { - Increased membership and fund-raising } \\
\text { base for organizational sustainability }\end{array}$ \\
\hline
\end{tabular}

resources, they also identified best practices that could be employed in the development of their proposed program. The group drew particular inspiration from the outreach activities conducted by the Michigan Farmers Market Association (MIFMA), specifically its Market Manager Certificate Program, which requires multiple inperson learning sessions that emphasize both content and manager networking; and the Michigan Market Manager Mentorship Program, which pairs market managers with experienced mentors to overcome challenges surrounding food access and the use of SNAP benefits (food stamps) at markets.

With the WV Community Development Hub as fiscal agent, the group applied for and received an US\$80,300, 18-month grant from the Claude Worthington Benedum Foundation to hire a fulltime program coordinator to implement pilot project activities. The technical assistance model proposed by the WVFMA was a multipronged approach that consciously engaged all levels of stakeholders through integrated components of group training and direct technical assistance, all in a schedule conducive to the seasonal time constraints of growers and of the volunteer market and WVFMA board members.

In 2012 the WVMFA formally launched the FMTNPP. Markets participated in a competitive selection process that evaluated their organizational stability and prior experience managing projects, clarity of need, willingness and ability to commit to the program requirements, and geographic distribution. Ten markets were chosen for participation in the pilot program. Markets received training in best practices in all four of the areas of need (see the Appendix) and on the importance and use of data (sales and visitation) tracking tools. To further add value to the training and resources provided around the broad areas of need, market representatives were paired with technical assistance providers for one-on-one assistance on a specific project. Similar one-on-one assistance was provided to each market to implement the tracking system in order to ensure consistency across all markets participating in the pilot. Markets were also eligible to receive minigrants of up to US $\$ 1,000$ midway through the two-year program to undertake projects related to their identified need.

Similar to the MIFMA's Market Manager Certificate Program, the FMTNPP included four statewide convenings. These meetings provided opportunities for educators and resource providers to present content related to the areas of need, and for market leaders to network and collaborate in regional subgroups. Convenings were held in different regions of the state; each one was cohosted by a well established market that could showcase its efforts to less established markets. 
The sequence of four statewide convenings was designed to build community, create enthusiasm for the established farmers markets that hosted the convenings, and encourage markets to remain accountable to follow through on plans and projects initiated at previous convenings.

To further improve the program and sustain learning and technical assistance beyond the grant period, the WVFMA committed to and developed online educational materials (Farmers Market Toolkit) based around educators' content and market experiences, using market data, and content generated by resource providers.

\section{Program Evaluation}

To ensure the effectiveness of the pilot program and identify areas for future improvement, the WVFMA in partnership with the WVU Extension Service collected program evaluation data at multiple points during the program. An intake tool asked two questions addressing market representatives' confidence in the long-term future of their market, and the development and use of long-term business plans; a midpoint and final evaluation included additional questions that assessed the FMTNPP's success in addressing market needs and challenges, improving sales, and connecting the markets to resources and technical assistance. Multiple market representatives completed evaluations; however, the final evaluation was completed by only nine of the 10 markets. The evaluation tool and sample size are not sufficient to draw statistically valid conclusions about the program's effectiveness; however, they do shed light on participants' satisfaction with program outcomes.

At the completion of the program all respondents reported increased confidence in the long-term future of their markets. Additionally, all respondents reported feeling more connected to existing resources and technical assistance, and as a result were better able to access information from experts and their peers. By matching the needs of the markets with technical resources, the FMTNPP began to address many of the challenges identified by participating markets at the start of the program: at the final evaluation, five markets indicated their challenges had been somewhat addressed, and four markets indicated their challenges had been addressed. Specific technical assistance programs, such as those focusing on low-cost season extension practices like low tunnels and row covers, were regarded as valuable. Four markets used minigrant funds to purchase equipment and supplies for their vendors to implement season extension practices, and one market held a workshop open to all growers in the county. The workshop was attended by 23 people and distributed row cover and other needed materials to nine market vendors. The market reported that vendor participation in the workshops helped increase both the quantity and variety of early and late produce, particularly salad greens, a high-value farmers market crop.

A challenge frequently cited by past literature (Connell \& Hergesheimer, 2014; Stephenson et al., 2008) and the FMTNPP's participating markets was the need for formalized business plans. Results from initial data collection indicated that only one of the 10 pilot markets had a long-term business plan. Over the course of the program, three markets worked one-on-one with business consultants to address long-term visioning, goal-setting, and budgeting. With the assistance of consultants, two of the markets crafted formal business plans based on input from their governing bodies. One smaller market utilized its consulting time to develop workshops for individual vendors. Additionally, one market used elements from its newly developed business plan to establish a consignment booth to incubate new producers and expand the market's reach in the community. The market used minigrant funds to hire a social media marketing manager to coordinate online communications, specifically those targeted to low-income consumers. The project is credited with attracting 31 new, regular SNAP customers, increasing market sales by 39 percent, and generating 100 new subscriptions to the market's e-newsletter.

In addition to the technical assistance, all 10 participating farmers markets received training and support on how to collect and submit sales data to WVFMA representatives. Use of the data collection toolkit generated robust data on gross sales, WIC and Senior Voucher Coupon sales, SNAP/ EBT sales, customer headcounts, vendor participation in data-gathering, and more. At the close of 
the 2012 market season representatives were presented with collective trends for the group and individualized reports for their market. This allowed the markets to benchmark and quantify their efforts and compare their progress to peers across the state. The reports were well received; 100 percent of the participants indicated they would continue to collect data after the pilot program's completion.

At the program's conclusion, all responding market representatives indicated that sales had improved (five markets) or somewhat improved (four markets) as a result of their participation in the program. An analysis of the data indicated a 13 percent increase in gross sales for the participating markets between 2012 and 2013; however, these increases cannot be directly attributed to program participation.

\section{Program Outcomes and Lessons Learned} Evaluation results suggest that the FMTNPP produced many successes regarding the needs and challenges of participating member markets. Even during implementation, however, program organizers recognized shortcomings and areas for improvement. The lessons learned during the pilot program led to improvements in program structure and content delivery for later program iterations and improved outcomes and impacts for stakeholders.

\section{Learning from Peers}

The importance placed on peer networking and peer learning to address market challenges is key feature of the FMTNPP. As the program developed, the emphasis on practitioners' expertise continued to expand and today is central focus of the program. With the exception of MIFMA's mentorship program, we are unaware of any similar programs nationwide. Additionally, the WVFMTNP was the only program that used the peer approach to address a breadth of market needs, as MIFMA's mentorship programs until this year were specific to food access needs.

Although the program's initial emphasis was a top-down, expert-led model focused on connecting market leaders to experts and/or consultants in high-need training areas, program coordinators quickly learned that "experts" often did not have a sufficient working knowledge of farmers markets and agriculture in general to adequately help the markets solve their issues. This was especially true for business and marketing consultants. Recognizing that the experiences of market leaders were often the best teaching tools, the WVFMA encouraged participants to mentor each other; however, no formal structure was created to facilitate this knowledge exchange. Without a structured approach, volunteer managers' time demands limited the amount of peer learning that occurred. Future convenings were modified specifically to include presentations by market participants on topics of expertise, as well as organized group activities and networking opportunities where participants could ask their peers for assistance, trouble-shoot challenges, and share successes. The current program also includes scheduled, mandatory monthly conference calls between WVFMA staff and all participating market representatives. Agendas include an "ask the expert" activity, where questions are posed to the group either by staff or other group members, and participants share advice, resources, and information. The success of the peer learning model has led to its use in other WVFMA initiatives, including the "New Vendor Launch," a producer development program that pairs producers with less than two years of experience with seasoned vendors.

\section{Training the Trainers}

In addition to encouraging leaning between peers, the next iteration of the program specifically included funding for consultants and WVFMA staff time to collaborate on the creation of Farmers Market Planning Toolkit modules to address highneed subject areas. The learning modules were structured so that could be used by both markets and service providers and consultants. Topics currently include "Marketing Your Market," "Structure, Management, and Finance," and "Vendor Recruitment and Retention." Authors and contributors include representatives from food and farm organization, state agencies, university Extension programs, and participating markets. These collaborations between content experts and farmers market leaders bridge the gap between 
technical assistance providers and the markets they are trying to help. The result is improved access to information for markets and more effective service provision by technical assistance providers. Iowa State University Extension has recently adapted and expanded the "Structure, Management, and Finance" module to apply to the specific needs of Iowa farmers markets and other local food organizations. Additional information on these resources is available through the WVFMA website

\section{(http://wvfarmers.org/).}

\section{Data Collection}

The data collection and submission process is key to successful program evaluation, especially when success is defined by customer attendance and vendor sales; unfortunately, time constraints and lack of perceived value limited market leaders' willingness to participate in the process. Data for the 2013-2014 market year was often spotty because of poor reporting. In later iterations of the WVFMTNP, the WVFMA hosted an in-person data collection during the kick-off meeting to help engage participants and minimize confusion. The group also hired staff to follow up with markets and ensure timely and accurate data submissions. As a result of these efforts, the WVFMA recorded 100 percent participation and submission for the 2014-2015 season.

Five of the markets participating in the 20122013 pilot returned to participate in the 2014-2015 program. Comparisons between 2012 and 2014 data for the five markets reveal a 150 percent increase in average customer attendance and approximately US $\$ 250,000$ in increased sales. SNAP/EBT acceptance increased from two markets in 2012 to five in 2014; SNAP/EBT receipts increased from US $\$ 296$ in 2012 to US $\$ 8,679$ in 2014 , a nearly 30 fold increase.

\section{Commitment}

The success of the FMTNPP requires significant time commitments from market managers and is most successful with buy-in from the vendors, organizers, and other stakeholders, especially for program elements such as data collection and submission. Due to WVU Extension's involvement in the program, several markets in the FMTNPP were represented by local agents. Unfortunately these markets were by far the lowest-performing of all the markets in terms of timely data submission, reporting, and participation in activities. As community "activators," the agents would often apply for grants or agree to participate in projects on behalf of their markets. However, other time commitments coupled with a lack of buy-in from market leaders and stakeholders ultimately caused these projects to suffer. Future rounds of the FMTNPP required that the primary program contact and the submitter for market and project data was an elected officer of the market, not an external party.

\section{Carrots, Sticks, and Strategic Requests}

Many small, rural markets have at most one paid manager, the majority of whom only work parttime, and few local stakeholders from whom to draw support. Program organizers recognized the need to manage expectations and be as strategic as possible when making requests, from communications to reporting. For example, in initial meetings the WVFMA provided monetary resources and helped secure resource providers, but asked market leadership to coordinate meeting logistics. As a result, many market leaders devoted time and resources to planning meetings rather than carrying out program requirements and implementing projects. The second round of programing relied on WVFMA staff to coordinate meetings, freeing market leaders to develop content and recruit vendors.

In addition to strategic requests, program leaders became more strategic in their use of resources and incentives to encourage compliance with program requirements. Incentives for the 2012 2013 pilot program included US $\$ 1,000$ toward markets' minigrant projects. Some markets received half the money in the spring of 2013 and the remainder upon completion of data reporting for the year. Others with capital-intensive projects were given US $\$ 900$ up front with the final US $\$ 100$ reserved for reimbursement. The markets that had 50 percent of their funding held back were much more diligent about reporting their data, and all completed their final reports. In contrast, two of the three markets who received 90 percent of their 
funding failed to fully report. Going forward the program has retained the 50/50 model to incentivize full participation in program requirements.

\section{Conclusions}

The lessons learned from the FMTNPP are valuable and have set the tone for forward movement in the organization and the state's regional food system development efforts. Pilot markets are continuing data collection and face-to-face networking. The program's success has led to the establishment of a formal training network based on the effective approaches learned. The network will allow the WVFMA to stay abreast of the emerging market training needs and available resources of service providers. The organization is expanding its educational reach through formalized Farmers Market Planning Toolkits and targeted education delivered at regional farm gatherings and market localities, reducing the time and financial burdens to markets. The hiring of a project coordinator is increasing the WVFMA's long-term organizational capacity, strengthening existing partnerships, creating economies of scale, and reducing duplication of services. Partnerships forged with other organizations and technical assistance providers have exposed these groups to the benefits and unique needs of farmers markets, thereby increasing the effectiveness of program delivery and strengthening the stability of West Virginia's farmers markets and local food economy.

The FMTNPP evaluation results suggest that the program was successful in connecting markets to needed technical resources, increasing markets' confidence in their own long-term future, and increasing sales. However, these successes required program leaders to consciously reflect on what did and did not work, and modify the program along the way. The lessons learned during the pilot program's implementation shed light onto what market leaders need and value in terms of training, expertise, and delivery. Specifically, these efforts revealed the value of peer learning and networking, the need to educate service providers and partners on the unique needs of markets and farm-based businesses, and the importance of incentives and managed expectations. These lessons have benefited future iterations of the program and all levels of market stakeholders and should benefit similar organizations and programs across the country.

\section{References}

Cameron, A. (2007). Farmers' markets as small business incubators and safety nets: Evidence from New

Zealand. International Journal of Entrepreneurial Behavior and Research, 13(6), 367-379. http://dx.doi.org/10.1108/13552550710829179

Connell, D. J., \& Hergesheimer, C. (2014). Strengthening the core business of farmers markets through strategic business planning. Journal of Agriculture, Food Systems, and Community Development, 4(4), 97-108. http://dx.doi.org/10.5304/jafscd.2014.044.017

Cowee, M. W., Curtis, K. R., \& Gatzke, H. (2009). Marketing farmers' markets: Ideas for market vendors and managers in Nevada (University of Nevada Cooperative Extension Special Publication 09-10). Retrieved from https://www.unce.unr.edu/publications/

Eggert, D., \& Farr, J. (2009). Farmers market manager training manual. Fayetteville: Farmers Market Federation of New York. Retrieved from http://www.nyfarmersmarket.com/wp-content/ uploads/2014/08/NYFM Training Manual.pdf

Feenstra, G. W., Lewis, C. C., Hinrichs, C. C., Gillespie, G. W., \& Hilchey, D. (2003). Entrepreneurial outcomes and enterprise size in US retail farmers' markets. American Journal of Alternative Agriculture, 18(1), 46-55. http://dx.doi.org/10.1079/AJAA2003046

Gardner, E. (2014). 2014 Farmers Market Census data bandout. Charleston: West Virginia Farmers Market Association. Retrieved from http:/ /wvfarmers.org/ get-involved/statewide-farmers-market-census/

Low, S. A., Adalja, A., Beaulieu, E., Key, N., Martinez, S., Melton, A.,...Jablonski, B. B. R. (2015). Trends in U.S. local and regional food systems (Administrative Publication No. 068). Washington, D.C.: United States Department of Agriculture, Economic Research Service. Retrieved from http://www.ers.usda.gov/publications/ ap-administrative-publication/ap-068.aspx

Project for Public Spaces. (2008). Diversifying farmers markets: New opportunities for farmers, communities and consumers. Retrieved from http://www.pps.org/pdf/Kellogg Final.pdf 
Spellman, K., Lyons, S., \& Lower, L. (2012). West Virginia Farmers Market Association - Increasing the functionality and viability of West Virginia's farmers markets and their producers. Grant submitted to the Claude Worthington Benedum Foundation.

Stephenson, G., Lev, L., \& Brewer, L. (2008). 'T'm getting desperate': What we know about farmers markets that fail. Renewable Agriculture and Food Systems, 23(3), 188-199. http://dx.doi.org/10.1017/S1742170507002153

Tropp, D., \& Barham, J. (2008). National farmers market summit proceedings report. Available from http://handle.nal.usda.gov/10113/38403

U.S. Department of Agriculture [USDA], Agricultural Marketing Service [AMS]. (2014). National count of farmers market directory listing graph: 1994-2014

[Graph]. Retrieved from http://dairyprogramhear ing.com/ams.fetchTemplateDatadb6adb6a.html

USDA, National Agricultural Statistics Service. (2014). 2012 Census of Agriculture: United States summary and state data (Report No. AC-12-A-51). Retrieved from http://www.agcensus.usda.gov/Publications/2012 /Full Report/Volume 1, Chapter 1 US/usv1.pdf Wasserman, W. (2009). Services, structures, and self-identified needs of state farmers market associations/organizations: $A$ survey summary report. Kimberton, Pennsylvania: Farmers Market Coalition. Retrieved from http://farmersmarketcoalition.org/wp-content/ uploads/2013/11/FINAL_FMA_Survey_Report_ wData.pdf 
Appendix. West Virginia Farmers Market Training Network Pilot Program's Identified High-need Subject Areas, Topics Covered During the Program, Market Resources, and Contributing Partners

\begin{tabular}{|c|c|c|c|}
\hline High-need Subject Areas & Topics Covered & Resources Provided & Contributors \\
\hline Risk Management & $\begin{array}{l}\text { - Insurance requirements } \\
\text { ○ When is insurance necessary? } \\
\text { ○ Selling at markets } \\
\text { ○ Selling at on-farm markets } \\
\text { - Types of insurance } \\
\text { ○ Liability insurance } \\
\text { - Homeowners insurance } \\
\text { - Where to purchase and how to shop } \\
\text { - Reducing risk }\end{array}$ & $\begin{array}{l}\text { - Factsheets and FAQ sheets } \\
\text { - PowerPoint presentations }\end{array}$ & $\begin{array}{l}\text { - WV Small Farm Center (Extension) } \\
\text { - WV Farm Bureau } \\
\text { - Fayette, Monroe, and Morgantown } \\
\text { Farmers Markets }\end{array}$ \\
\hline $\begin{array}{l}\text { Business Planning and } \\
\text { Marketing }\end{array}$ & $\begin{array}{l}\text { - Brand strategy development } \\
\text { - Signage and graphics } \\
\text { - Earned media } \\
\text { - Social media } \\
\text { - Events }\end{array}$ & $\begin{array}{l}\text { Direct technical assistance in business plan } \\
\text { development. } \\
\text { - Examples of successful WV marketing } \\
\text { - Surveys } \\
\text { - MESH Brand brainstorm survey } \\
\text { - Target audience survey } \\
\text { - Print vendor resources } \\
\text { - How-to guide for media outreach } \\
\text { - Storytelling toolbox } \\
\text { - Social media strategy planning document } \\
\text { - Event planning guide }\end{array}$ & $\begin{array}{l}\text { - WVFMA board and staff } \\
\text { - MESH Design and Development } \\
\text { - Value Chain Cluster Initiativea } \\
\text { - Charleston Gazette } \\
\text { - Dream Creative } \\
\text { - Charleston Area Alliance }{ }^{b}\end{array}$ \\
\hline $\begin{array}{l}\text { Producer Development } \\
\text { and Vendor Recruitment and } \\
\text { Retention }\end{array}$ & $\begin{array}{l}\text { - Vendor recruitment } \\
\circ \text { Targeting growers } \\
\circ \text { Barriers to recruitment } \\
\circ \text { Orienting and integrating new } \\
\text { vendors } \\
\text { - Vendor retention } \\
\circ \text { Market culture } \\
\circ \text { Participation and trust } \\
\circ \text { Managing funds } \\
\circ \text { Engaging customers } \\
\circ \text { Investing in vendor education and } \\
\text { growth } \\
\text { - Season extension techniques }\end{array}$ & $\begin{array}{l}\text { - Direct technical assistance on season } \\
\text { - } \text { Vextension, including high and low tunnels } \\
\text { - Example vendor application } \\
\text { - Example of rules and grievance policy } \\
\text { - Planning worksheet for good and transparent } \\
\text { governance } \\
\text { - Surveys } \\
\text { O Designing dot surveys } \\
\text { - Vendor interest in education }\end{array}$ & $\begin{array}{l}\text { - Value Chain Cluster Initiativea } \\
\text { - WVFMA board and staff } \\
\text { - Wild Ramp, Williamson, and Putnam } \\
\text { County Farmers Markets } \\
\text { - WVU Extension Service } \\
\text { t }\end{array}$ \\
\hline Structure and Unity & $\begin{array}{l}\text { - Defining the organization } \\
\text { - Mission and vision }\end{array}$ & $\begin{array}{l}\text { - Sample mission and vision statements } \\
\text { - Stakeholder analysis worksheet }\end{array}$ & $\begin{array}{l}\text { - WVFMA board and staff } \\
\text { - WV Food and Farm Coalition }\end{array}$ \\
\hline
\end{tabular}

Orienting and integrating new

Participation and trust

- Stakeholder analysis worksheet
WV Food and Farm Coalition 


\begin{tabular}{|c|c|c|c|}
\hline High-need Subject Areas & Topics Covered & Resources Provided & Contributors \\
\hline & $\begin{array}{l}\text { - Stakeholders } \\
\text { - Goal setting and strategic plans } \\
\text { - Effective facilitation } \\
\text { - Legal structure } \\
\text { ○ Nonprofits vs for-profits } \\
\text { ○ Cooperatives } \\
\text { ○ State and federal filings } \\
\text { - Governance } \\
\text { ○ Bylaws } \\
\text { ○ Rules } \\
\text { - Membership } \\
\text { - Building a board of directors } \\
\text { - Funding the market } \\
\text { ○ Vendor fees or commissions } \\
\text { ○ Merchandise sales } \\
\text { ○ Donations } \\
\text { ○ Sponsorships } \\
\text { ○ Crowdfunding } \\
\text { ○ Grants }\end{array}$ & $\begin{array}{l}\text { - Board member commitment form } \\
\text { - Strategic planning template } \\
\text { - Sample bylaws from } 501(c)(3) \text { market } \\
\text { - Secretary of State nonprofit registration } \\
\text { - Strategic planning template } \\
\text { - Mission and vision group activity } \\
\text { - Member recruiting matrix } \\
\text { - Fundraising plan template } \\
\text { - FM budget template }\end{array}$ & $\begin{array}{l}\text { - Office of WV Secretary of State } \\
\text { - WVU Extension } \\
\text { - WVU College of Law } \\
\text { - Ohio Cooperative Development Center } \\
\text { - Morgan County Association for Food and } \\
\text { Farm }\end{array}$ \\
\hline
\end{tabular}

a The Value Chain Cluster Initiative provides hands-on business development and coaching services to new or existing producers, processors, aggregators, and distributors of local food in 17 West Virginia counties.

b Charleston Area Alliance is a regional Chamber of Commerce that also provides workforce development and small-business support services. 